\title{
Feline Leishmaniasis: A Review on Epidemiology, Diagnosis and Treatment
}

\author{
Bruna Mauri Dias' ${ }^{1}$, Luis Fernando Rezende Flegler'1, Maria Eduarda Pandini Foletto', \\ Luiza Corteletti Torezani ${ }^{1}$, Ana Clara Chagas da Silva', Maira Damaceno Ribeiro', \\ Mariana Caetano Teixeira ${ }^{2}$, Clairton Marcolongo Pereira ${ }^{{ }^{*}}$
}

\footnotetext{
${ }^{1}$ Faculty of Veterinary Medicine, Centro Universitário do Espírito Santo (UNESC), Colatina, Brazil

${ }^{2}$ Faculty of Veterinary Medicine, Centro Universitário Ritter dos Reis (UniRitter), Porto Alegre, Brazil

Email: *clairton.marcolongo@terra.com.br
}

How to cite this paper: Dias, B.M., Flegler, L.F.R., Foletto, M.E.P., Torezani, L.C., Chagas da Silva, A.C., Ribeiro, M.D., Teixeira, M.C. and Pereira, C.M. (2021) Feline Leishmaniasis: A Review on Epidemiology, Diagnosis and Treatment. Open Access Library Journal, 8: e7337.

https://doi.org/10.4236/oalib.1107337

Received: March 22, 2021

Accepted: April 19, 2021

Published: April 22, 2021

Copyright $\odot 2021$ by author(s) and Open Access Library Inc.

This work is licensed under the Creative Commons Attribution International License (CC BY 4.0).

http://creativecommons.org/licenses/by/4.0/

\begin{abstract}
Leishmaniasis is an infectious disease caused by the protozoan of the genus Leishmania. It is a tropical disease, considered endemic worldwide and the natural infection occurs through the bite of infected sandflies of the genus Lutzomya. Dogs are considered the main zoonotic reservoirs of this parasite and cats are considered to be potential reservoirs of this disease. Thus, the objective of the study was to review the epidemiology, clinical and laboratory findings, diagnosis, differential diagnosis and treatment of feline leishmaniasis.
\end{abstract}

\section{Subject Areas}

Veterinary Medicine

Keywords

Feline, Lesihamania spp., Epidemiology, Clinical Signs, Review

\section{Introduction}

Leishmaniasis is an infectious disease of parasitic origin and of a zoonotic character, caused by protozoa of the genus Leishmania [1]. The disease is classified as a neglected tropical disease because it is considered endemic in low-income populations and because there is little investment in research, drug production and incentives for measures to control the disease [2].

These protozoa belong to the order Kinetoplastida, Family Trypanosomatidae and genus Leishmania [3]. Leishmaniasis is a complex of diseases caused by a heteroxenous cycle protozoan that, in its amastigote form, are obligatory intra- 
cellular parasites of the mononuclear phagocytic system of mammalian hosts. In invertebrates, the protozoan has a promastigote shape, located in the intestine of these hosts [4].

Leishmaniasis has two forms of clinical manifestation described and known as cutaneous and visceral. The cutaneous presentation is caused by the infection of L. brasiliensis, L. guyanensis and L. (Mexicana) amazonenses [5]. The visceral presentation is caused by Leishmania infantum chagasi [6]. Dogs are considered the main reservoir for this parasite [4] and cats have been considered as potential reservoirs for this disease [7].

The increased preference for cats as pets and the greater proximity of these animals to man has demonstrated the importance of studies on the diseases that cover felines. Thus, the objective of the present study is to review the epidemiology, clinical and laboratory findings, diagnosis, differential diagnosis and treatment of feline leishmaniasis.

\section{Epidemiology}

Leishmaniasis in cats has been reported sporadically in several parts of the world, but the role of these animals as a reservoir of the disease has not been completely clarified [2]. Some recent studies on the transmission of leishmaniasis have shown that insects bred in the laboratory, free from Leishmania spp. infection, can become contaminated by ingesting blood from cats infected with the parasite [8] [9].

Leishmaniasis transmission occurs through the inoculation of metacyclic promastigote forms during the blood meal of the phlebotomine Lutzomia Iongipalpis infected with the parasite [10]. This mosquito is popularly known as the sand fly and its life cycle is linked to areas with accumulation of organic matter [11]. In addition to L. longipalpis, new phlebotomes involved in the Leishmania cycle have been increasingly described and researched in numerous regions of Brazil. This is the case of Psychodopygus lloydi, Pintomyia fischeri, Lutzomyia amarali, Nyssomyia whitmani and Migonemyia migonei [1] [11] [12].

When the metacyclic promastigote forms are sought in the vertebrate host, these forms invade the cells of the phagocytic mononuclear system, transform into amastigote forms and spread through the bloodstream and lymph to various organs, such as the liver, spleen, bone marrow and the lymph nodes (Figure 1). Through mechanisms of survival and evasion of the immune system, leishmanias guarantee their chronic permanence with or without the development of clinical manifestations in the hosts [13].

Direct transmission of leishmaniasis has no epidemiological importance. Blood transfusion can be a form of leishmaniasis infection for humans, cats and dogs [14].

\section{Clinical Findings}

Most cats are asymptomatic and have hematological and biochemical tests 


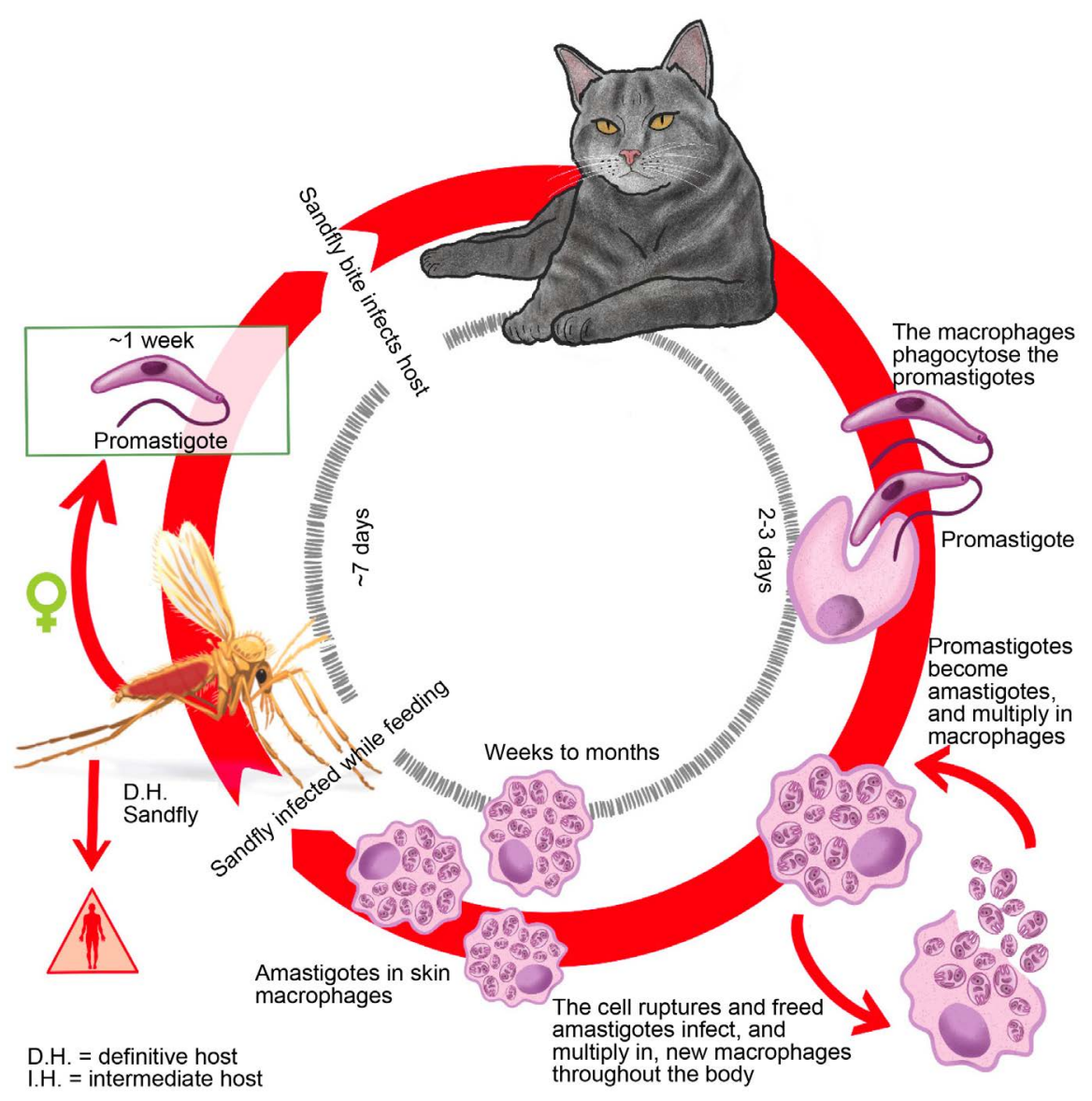

Figure 1. Cat infected with Leishmania promastgota forms; Promastigated forms invade and transform into amastigotes and multiply within macrophages; There is a rupture of the cell wall of these macrophages, spreading the amastigote forms to the bloodstream and lymph; Amastigost forms look for new macrophages to multiply; The phlebotome comes and feeds on the host, becoming infected; the phlebotome bites a new host, infecting it. [Based on 15].

within the normal range [16]. This characteristic is probably due to the chronic nature of the disease.

In some cases, hyperproteinemia may occur, due to the increase in gamma globulins [12].

Infected cats can present ulcerated lesions with the presence of blood in the snout region, nodules at the edges of the ears, cachexia, alopecia, pale mucous membranes, uveitis, conjunctivitis, blepharitis and ocular keratitis [17]. In some rare cases, ulcerated lesions on the body can be seen [18]; jaundice hypoalbuminemia, polyuria, polydipsia and pancytopenia [19]. In addition, some visceral signs can be observed, such as: lymphadenopathy, hepatomegaly, splenomegaly, and renal insufficiency [12].

Some nonspecific clinical manifestations can also be observed, such as fever, vomiting, diarrhea, nasal discharge, dyspnea, abortion, gingivostomatitis and lymphadenomegaly [20].

The main laboratory changes are described in Table 1. 
Table 1. Main laboratory changes observed in Feline Leishmaniasis.

\begin{tabular}{ccc}
\hline Frequent changes & Less frequent changes & Rare changes \\
\hline & & Azotemia \\
Hypergammaglobulinemia & Proteinuria & Hypoalbuminemia \\
Lymphadenopathy & Non-regenerative anemia & Monocytosis \\
& & Neutrophilia \\
& Pancytopenia \\
\hline
\end{tabular}

\section{Diagnosis}

The diagnosis of Leishmaniasis in cats must be made based on the animal's history, the epidemiological context in which it is found, the clinical signs, the results of the complementary methods of diagnosis and exclusion of the differential diagnoses [19].

The diagnosis of the disease in felines is based on the same methods available for canines. Diagnosis can be made through serology, cytological and histopathological exams and PCR [7].

Cytological examination is a highly specific, non-invasive, fast, low-cost and simple diagnostic method that can be performed in cynics and has a $50 \%$ sensitivity for the diagnosis of feline leishmaniasis [7]. In cytology, the amastigote forms of the parasite are observed. This method is considered the gold standard, even with less sensitivity [7].

Serological methods alone may not be sufficient for the diagnosis of leishmaniasis in felines due to the delay in seroconversion in these animals and the low rate of antibody production [21]. Animals that show immunocompromise due to retrovirus infection may show inconsistent serological results [21]. Quick tests for the diagnosis of leishmaniasis in dogs are not efficient in diagnosing this disease in cats, and can generate cross-reactions with other protozoa [22].

PCR has better sensitivity and specificity than cytology and serological tests for the diagnosis of the disease in cats. However, some studies indicate that cats with high levels of anti-Leishmania antibodies are less positive in PCR tests. In addition, the collection location (bone marrow or blood) can influence the results of the exam [7].

\section{Differential Diagnosis}

The main differential diagnoses of feline leishmaniasis are squamous cell carcinoma, pyodermatitis, sporotrichosis, pemphigus foliaceus, lupus erythematosus, zinc-responsive dermatosis, migratory necrolytic erythema, sebaceous adenitis, lymphoma and eosinophilic granuloma [23] [24] [25].

\section{Treatment and Prevention}

There is no established treatment protocol for feline leishmaniasis. The treatment of cats is based on the clinical experience of published case reports and the off-label use of the most common drugs prescribed to dogs [7]. 
Allopurinol is a drug widely used in the treatment of canine leishmaniasis because it inhibits the metabolism of purines, exerting an inhibitory effect on the growth of Leishmania. allopurinol shows clinical improvement in most cats treated with this drug [26].

Miltefosine is another medication used to treat dogs with leishmaniasis that has been used to treat cats with this disease. Miltefosine inhibits the growth of promastigote forms of the parasite and causes the death of amastigote forms, resulting in high leishmanicidal activity [7] [27].

The use of collars based on pyrethroids has demonstrated great efficacy in the control of canine leishmaniasis. However, most pyrethroids are toxic to cats and the only pyrethroid indicated for this species in collars is flumethrin [14] [19]. In addition, the use of topical insecticides available for cats has not been shown to be effective in preventing phlebotome mosquito bites in endemic areas [14].

This research, however, is subject to several limitations. The main limitations of this study, as with all review studies, are its variability the management and diagnosis of each case. Extensive clinical information was not available for all studies and there was inconsistency in the follow-up periods, treatment recommendations and evaluations of the cases, making it more difficult to draw solid conclusions.

\section{Conclusion}

It is noteworthy in this study that the domestic cat is susceptible to infection by Leishmania spp. and it can become an accidental reservoir of the parasite and spread the disease. Feline leishmaniasis should be included in the differential diagnosis of feline infectious diseases, especially in endemic regions for canine leishmaniasis. The methods of diagnosis, treatment and control of feline leishmaniasis are the same as those used for canine leishmaniasis, however, there are few studies that prove the effectiveness of drugs in the treatment of the disease in cats.

\section{Acknowledgements}

This work was supported by Fundação de Amparo à Pesquisa e Inovação do Espírito Santo (FAPES), and was financed in part by the Coordenação de Aperfeiçoamento de Pessoal de Nível Superior (CAPES), Brasil-Finance code 001.

\section{Conflicts of Interest}

All authors declared that they do not have any conflict of interest to disclose.

\section{References}

[1] Lavitschka, C.O., Ceretti Jr., W. and Marrelli, M.T. (2018) Occurrences of Phlebotomine Sand Flies (Diptera: Psychodidae) Potentially Associated with Leishmaniasis Transmission in Urban Parks in the City of São Paulo, Brazil. Journal of the American Mosquito Control Association, 34, 151-153.

https://doi.org/10.2987/18-6735.1 
[2] Longoni, S.S., López-Cespedes, A., Sánchez-Moreno, M., et al. (2012) Detection of different Leishmania spp. and Trypanosoma cruzi Antibodies in Cats from the $\mathrm{Yu}$ catan Peninsula (Mexico) Using an Iron Superoxide Dismutase Excreted as Antigen. Comparative Immunology, Microbiology and Infectious Diseases, 35, 469-476. https://doi.org/10.1016/j.cimid.2012.04.003

[3] Gurgel, I.G.D.A. (2007) Scientific Research in Driving Vector-Borne Disease Control Policies. Thesis (Doctorate in Public Health), Centro de Pesquisas Aggeu Magalhães, Fundação Oswaldo Cruz.

[4] Gramiccia, M. (2011) Recent Advances in Leishmaniosis in Pet Animals: Epidemiology, Diagnostics and Anti-Vectorial Prophylaxis. Veterinary Parasitology, 181, 23-30. https://doi.org/10.1016/j.vetpar.2011.04.019

[5] Pezente, L.G. and Benedetti, M.S.G. (2019) Pidemiological Profile of American Tegumentary Leishmaniasis in the State of Roraima, Amazônia, Brasil, entre 2007 e 2016. Brazilian Journal of Health Review, 2, 1734-1742.

http://www.brjd.com.br/index.php/BJHR/article/view/1458/1558

[6] Cipriano, R.S., Maciel, M.O.S. and Cardoso, G.C.D. (2018) Serological and Clinical Aspects of Seropositive Dogs for Visceral Leishmaniasis in the Municipality of Araçatuba, São Paulo, Brasil. Revista de Educação Continuada em Medicina Veterinária e Zootecnia do CRMV-SP, 16, 78.

[7] Fernandez-Gallego, A., Feo Bernabe, L., Dalmu, A., et al. (2020) Feline Leishmaniosis: Diagnosis, Treatment and Outcome in 16 Cats. Journal of Feline Medicine and Surgery, 22, 993-1007. https://doi.org/10.1177/1098612X20902865

[8] Batista, J.F., Neto, F.C.R.M., Lopes, K.S.P.P., et al. (2020) Transmission of Leishmania infantum from Cats to Dogs. Revista Brasileira de Parasitologia Veterinária, 29, No. 4. https://doi.org/10.1590/s1984-29612020099

[9] Coura, F.M., Passos, S.K.P., Pelegrino, M.O.F., et al. (2018) Serological, Molecular and Microscopic Detection of Leishmania in Cats (Felis catus) in Belo Horizonte, Minas Gerais, Brasil. Revista Brasileira de Parasitologia Veterinária, 27, 570-574. https://doi.org/10.1590/s1984-296120180052

[10] Persichetti, M.F., Solano-Gallego, L., Vullo, A., et al. (2017) Diagnostic Performance of ELISA, IFAT and Western blot for the Detection of Anti-Leishmania infantum Antibodies in Cats Using a Bayesian Analysis without a Gold Standard. Parasites \& Vectors, 10, Article No. 119. https://doi.org/10.1186/s13071-017-2046-3

[11] De Carvalho, M.R., Valença, H.F., Silva, F.J., et al. (2010) Natural Leishmania infantum Infection in Migonemyia Migonei (França, 1920) (Diptera: Psychodidae: Phlebotominae) the Putative Vector of Visceral Leishmaniasis in Pernambuco State, Brazil. Acta Tropica, 116, 108-110. https://www.arca.fiocruz.br/handle/icict/21013 https://doi.org/10.1016/j.actatropica.2010.03.009

[12] Garrido, J.M.D.C.B. (2012) Contribution to the Study of the Prevalence of Leishmania infantum Infection in Domestic and Stray Cats in the Districts of Lisbon and Viseu. Master's Dissertation, Universidade Técnica de Lisboa, Faculdade de Medicina Veterinária, Lisboa. http://hdl.handle.net/10400.5/4948

[13] Pereira Da Fonseca, I., Saraiva-Marques, C., Basso, A. and Garrido, J. (2013) Feline Leishmaniasis. Journal AEFMV, 67, 15-25.

[14] Espanha (2019) Canine and Feline Leishmaniasis Leishvet. http://www.leishvet.org/wp-content/uploads/2018/09/PO-Guidelines.pdf

[15] Beugnet, F., Halos, L. and Guillot, J. (2018) Textbook of Clinical Parasitology in Dogs and Cats. Servet Editorial-Grupo Asís Biomedia, S.L.

[16] Souza, A.I., Nunes, V.L.B., Borralho, V.M. and Ishikawa, E.A.Y. (2009) Domestic 
Feline Cutaneous Leishmaniasis in the Municipality of Ribas do Rio Pardo, Mato Grosso do Sul State, Brazil: A Case Report. Journal of Venomous Animals and Toxins Including Tropical Diseases, 15, 359-365. https://doi.org/10.1590/S1678-91992009000200017

[17] Alves, M.L. (2016) Occurrence of Visceral Leishmaniasis in Dogs and Cats in Animal Shelters in Ilha Solteira, SP. Master's Dissertation. Universidade Estadual Paulista, Faculdade de Engenharia, Ilha Solteira. http://hdl.handle.net/11449/138242

[18] Pinto, P.M.F. (2013) Prevalence of Infection by Leishmania sp. in Cats Resident in the Municipality of Cascais. Master's Dissertation, Lisboa. http://hdl.handle.net/10437/4837

[19] Sequeira, C.I.L. (2021) Leishmania spp./Leishmaniasis Infection in Cats in the Setubal Peninsula. Master's Dissertation, FMV-Universidade de Lisboa, Lisboa.

[20] Padua, E.D. (2017) Research of Anti-Leishmania Immunoglobulins and Clinical Evaluation of Cats Living in Endemic Areas of Rio de Janeiro. Dissertation (Master in Veterinary Medicine-Pathology and Clinical Sciences). Instituto de Veterinária, Universidade Federal Rural do Rio de Janeiro, Seropédica.

https://tede.ufrrj.br/jspui/handle/jspui/2431

[21] Sanches, A., Pereira, A.G. and Carvalho, J.P. (2011) A Case of Feline Leishmaniasis. Veterinary Medicine, 63, 29-30.

[22] Mendonça, H.F. (2019) Leishmaniasis in Domestic Cats (Felis catus). Advisor: Tatiana Guerrero Marçola. 22f. Course Completion Paper (Bachelor in Veterinary Medicine)-Centro Universitário do Planalto Central Apparecido dos Santos. https://dspace.uniceplac.edu.br/handle/123456789/196

[23] Gontijo, B.B., et al. (2011) Sporotrichosis and Tegumentary Leishmaniasis in Dogs and Cats: Similarities and Diferences. PUBVET, Londrina, 5, 1250.

[24] Maia, C., Ramos, C., Coimbra, M., et al. (2015) Prevalence of Dirofilaria immitis Antigen and Antibodies to Leishmania infantum in Cats from Southern Portugal. Parasitology International, 64, 154-156. https://doi.org/10.1016/j.parint.2014.11.006

[25] Pennisi, M.G. and Persochettip, M.F. (2018) Feline Leishmaniosis: Is the Cat a Small Dog? Veterinary Parasitology, 251, 131-137. https://doi.org/10.1016/j.vetpar.2018.01.012

[26] Nery, G., Becerra, D.R.D., Borja, L.S., et al. (2017) Evaluation of Lutzomyia Longipalpis Parasite Infectivity by Xenodiagnosis in Dogs Treated for Naturally Acquired Visceral Leishmaniasis. Pesquisa Veterinária Brasileira, 37, 701-707. https://www.arca.fiocruz.br/handle/icict/25510 https://doi.org/10.1590/s0100-736x2017000700009

[27] Vides J.P. and Moraes, L.R.S. (2018) Treatment of Canine Visceral Leishmaniasis with Miltefosine-Case Reports. Revista de Educação Continuada em Medicina Veterinária e Zootecnia do CRMV-SP, 16, 80. 